\title{
A Comparative Study on Literature of Urban Park Research Published During 1983-2013
}

\author{
LUO Tianqing ${ }^{1,}$, CHEN Ru ${ }^{1, b}$ and LIANG Juxia ${ }^{1, c}$ \\ ${ }^{1}$ Department of Landscape Studies, Tongji University, 1239 Siping Road, Shanghai, China, 200092 \\ aluotq@tongji.edu.cn, ${ }^{\mathrm{b}} 08$ chenru@tongji.edu.cn, ${ }^{\mathrm{c}} 1332205 @$ tongji.edu.cn
}

Keywords: Urban park, research evolution, research interest, landscape architecture, co-word analysis

Abstract. Urban parks are natural refuges and public recreational resources in municipalities. The profession of landscape architecture was established during the nineteenth-century urban park movement and has been taking developments of the urban park system as its main mission ever since. Experts from various professional areas joined in this field and expanded the professional concerns. Potential differences of their research interest may promote landscape architects to further understand the roles of urban parks in the changing world. This study applied co-word analyses to identify major issues addressed by documents on urban parks that were published in Landscape Journal during 1983-2013 or indexed by Web of Science Core Collection during 1994-2013. The results showed that experts from other professions provided more extensive and in-depth exploration in urban park research besides 'professional practices'. Such useful facts and knowledge can improve practices in landscape architecture and impel landscape architects to shoulder more social responsibilities.

\section{Introduction}

As important components of the green infrastructure and public recreation system in cities, urban parks sustain the quality of people's everyday life. High-quality parks create economic, social and environmental value in an urban situation by providing attractive public landscape to benefit the local economy, improving physical and mental health of residents, reducing crime and fostering social ties in communities, as well as positively impacting the nature system [1].

In modern history, various movements promoted the development of urban parks. The nineteenth-century urban park movement in England and North America shaped modern parks for public using [2]. The early twentieth-century reform park movement and the later recreation movements created types of national, regional and local parks to satisfy increasingly diverse recreational demand [3][4]. The amount of urban parks increased, various park types appeared and park design began to be standardized [3].

The development of urban parkland has been stagnant under the challenges of urban sprawl, population growth and suburbanization from the second half of the twentieth century, especially in countries under rapid industrialization and urbanization (e.g., the United Kingdom [5] and the United States [6]). However, the coming Leisure Time Era that was predicted by Molitor is witnessing more and changing recreational pursuits [7]. These pursuits, together with those generated by new lifestyles, value systems, attitudes to nature and sustainability in the 21 st century, need to be accommodated by the diverse, democratic provision of parks with contemporary understandings [8].

Landscape architects are the professional academics and practitioners working on urban parks. The profession of landscape architecture was established during the building of New York City's Central Park [9] and has been taking developments of the urban park system as its main mission ever since. Confronted with the new demand for urban park provision, landscape architects should take action.

Research has been addressing issues corresponding to the changing world, presenting facts and knowledge that acting on park design and then promoting the development of urban parks. Such action can be perceived in Cranz's narration [3] on the successive process of urban park development in the United States. Although research has become an integral part of landscape architecture programs after the continued growth and change in the profession [10], the amount of research 
published in peer-reviewed journals by landscape architecture faculty remains dismally low [11]. Meanwhile, the profession is demanding for multi-disciplinary collaborations on sustainable urban development and other experts than landscape architects began joining [12]. They are bringing substantial publications.

This paper operated a literature study of leading research on urban parks that was published by two groups of expert (i.e., landscape architects and experts from other disciplines) over the last three decades. The aims of the study are (1) to examine the evolution of publications on urban park studies and the major issues addressed by them, which may present the changing concerns for urban parks over recent decades; (2) to explore the potential differences of research interest between the two expert groups and nurture landscape architects with fresh ideas; and (3) to help landscape architects further understanding sustainable developments of the urban park system and reflecting on their responsibilities.

\section{Method}

Recent academic literature in special sources may provide a record of up-to-date research that was finished by landscape architects or other experts [11]. This paper counted their yearly publications on urban parks and applied co-word analyses to titles, keywords and abstracts of the documents to frame clusters of issues. In order to see how the results differed between the two expert groups and changed over time, documents were grouped according to the sources and then sub-grouped into periods. The co-word analyses were operated in each group.

Sources of Academic Publications. Landscape Journal $(L J)$ is the official journal of the Council of Educators in Landscape Architecture in the United States. In publication from 1982, it continues to be a valuable resource for academics and practitioners. This study took it as a representative source of leading research published by landscape architects. Totally 83 articles on urban park that were published in the journal between 1983 and 2013 were retrieved by smart group in EndNote X7.

The Web of Science Core Collection (WSCC) provides access to the world's leading citation databases that covers the highest impact, authoritative and multidisciplinary journals worldwide. Totally 1344 articles and proceeding papers on urban park that were published between 1994 and 2013 were retrieved from this collection. The diverse research areas of the documents (see Fig. 1) indicate that these papers could be a reflection of leading research published by experts from various disciplines.

Record Groups. Retrieved records from $L J$ and WSCC were analyzed in separate groups in order to perceive the differences of research interest between landscape architects and experts from other disciplines. For each group, records were further sub-grouped according to the published year in order to help understanding the evolution over the decades. Records between 1994 and 2013 that were retrieved from either source were divided into four consecutive sub-periods: 1994-1998, 1999-2003, 2004-2008 and 2009-2013. The rest records published in $L J$ between 1983 and 1993 were taken as a separate sub-group. Table 1 lists all the groups and the record counts in each group.

Usually there are two ways to select the time spans for the sake of sub-group analyses. If the selection is based on the number of target documents published per period (e.g., Dehdarirad, Villarroya, and Barrios [13]), the time spans will be different but the record numbers will be balanced between the groups. The balanced records may improve the reliability of analyses. The other selection is based on the equational division of periods (e.g., Zhang et al. [14]) with relatively unbalanced record distribution. The equal time spans may help to observe characteristics of changes over time. In order to explore the evolving research interest, this study adopted the equational time spans.

Table 1. Paper groups and the paper counts in each group

\begin{tabular}{lrrrrrr}
\hline & $1989-1993$ & $1994-1998$ & $1999-2003$ & $2004-2008$ & $2009-2013$ & Total \\
\hline$L J$ & 21 & 8 & 18 & 22 & 14 & 83 \\
WSCC & - & 58 & 121 & 314 & 851 & 1344 \\
\hline
\end{tabular}


Co-word Analysis. Co-word analysis is a relatively accurate tool for content analysis that uses statistical frequencies of pairs of words to reveal different research areas and interest [13]. Its methodological foundation is the idea that the co-occurrence of words describes the contents of the documents more exactly than frequency ranking of the words. By measuring the relative intensity of these co-occurrences with a matrix and achieving simplified representation of word networks with co-keyword clusters, the most common issues of relevant research can be identified.

Keywords are the words that academics use to reveal the internal structure of a paper's content and that are commonly analyzed in co-word analyses. In this study for the co-word analyses, author-provided keywords (or keywords plus in those instances where no author-provided keywords were available) were extracted from the records that were retrieved from WSCC. But most documents that were published in $L J$ do not present any keywords. Thus for the records from this journal, words extracted from the titles, keywords and abstracts were analyzed. The special word frequency statistic software ROST was used to calculate the frequency of the words and to construct a co-word matrix with the co-occurrences of the most common words. This co-word matrix was in turn used for clustering calculations in SPSS 18.

Words from different documents should be modified to avoid phraseological or redundant error that would influence the accuracy of analysis. In this study, the modification was focused on the most common words that would be involved in the co-word matrix to improve the efficiency of analysis. Different expressions for words with the same root and meaning were recorded. The topic words that were used for the retrieval were omitted from the analysis. Place names were omitted as well. After the modification, the frequency of the words was calculated again to create the co-word matrix.

The co-word matrix was firstly constructed from the co-occurrences of each pair of common words. The matrix was then translated into an equivalence index matrix [15] to avoid the bias between those words used frequently and those used less often. The translation from one matrix to the other was done according to the following equation:

$$
E_{i j}=\left(C_{i j}^{2}\right) /\left(C_{i} \times C_{j}\right) \text {. }
$$

Here Eij is the equivalence index of the words $\mathrm{i}$ and $\mathrm{j}$; $\mathrm{Cij}$ is the number of co-occurrences of the words $\mathrm{i}$ and $\mathrm{j}$; while $\mathrm{Ci}$ and $\mathrm{Cj}$ are the number of occurrences of the word $\mathrm{i}$ and $\mathrm{j}$ respectively. The equivalence index matrix was then used with the statistical software SPSS 18 and clustered with a Hierarchical Cluster Analysis. Each cluster of the common words thus reflected a research focus of relative publications.

\section{Results}

Yearly Publications in the Two Sources. Fig. 2(a) illustrates the numbers of retrieved records that were published in $L J$ every year, while Fig. 2(b) illustrates those were indexed by WSCC every year. The counts of research on urban parks published by the journal kept relatively stable, while those in the collection increased rapidly.

Frequencies of Associated Words in Urban Park Documents. For each group of records, the top words with higher frequencies were selected for the further co-word analysis after phraseological or redundant errors were corrected (see Table 2). The word frequencies varied from 3 to 128.

The results of the co-word cluster analysis are shown as tree charts in Fig. 3 and Fig. 4. The shorter the distance between the words, the closer the relationship between them.

Clustering of Associated Words into Major Issues. Using the proximity thresholds as references (the vertical dashed lines tagged with the distance value in Fig. 3 and Fig. 4), the selected words were divided into clusters with horizontal dashed lines in Fig. 3 and Fig. 4. The proximity value was a cut-off value used to identify the number of clusters before a total aggregation under one cluster. Major issues related to urban park research were then interpreted from clusters of selected words for each group (see Table 3). 


\section{Discussion}

Literature reviews of published papers on particular topics provide researchers with considerable data for the development of theoretical frameworks related to landscape architecture. For instance, Fabos [16] described the origins and recent case studies of greenway planning in the United States through an extensive literature review from the late 19th century. Co-word analysis is a powerful technique to enable comparisons of large document sets across knowledge domains. Nobis and Wohlgemuth [17] performed several word and co-word analyses on titles and abstracts of articles that appeared in five core journals of ecology over 25 years to objectively detect principal trends in the discipline. In this work, statistical results were obtained from analyzing relationships between words in titles, keywords and abstracts of 1427 documents about urban park research during the recent three decades to detect the evolution of research on urban parks and to compare the different research interest between landscape architects and other experts.

The frequencies of word occurrences in the documents can reflect the importance of themes [13]. So the reliability of results depends largely on how to select proper words of higher frequencies. Too many selected words would direct to discrete topics and disturb the analysis, while insufficient words would be incapable of addressing research interest objectively. The selection should be made according to a balance between the frequencies and amount of selected words, based either on researchers' experience or on formulas to be verified [18]. For example, according to Zipf's law of occurrences for words of low frequency, Donohue [19] put forward a formula to calculate the critical value of word frequency for identifying words of high frequency. But in this study, trial calculations with this formula resulted in unsatisfactory values. In each record group, the calculated value was higher than the frequencies of most or even all words. Thus for each group, top words of high frequency were judged by determination of experience.

Research Interest in Urban Parks. According to the subjects discussed in issues, some of the major issues in Table 3 can be related to the same theme. For instance, the theme, 'professional practices', can be related to the issues of 'design', 'plan', 'practice', 'management' and 'model' because designing, planning, practicing and managing are types of work for landscape architects, while models are powerful tools of the professional work. Similarly, the theme, 'park use', can be related to the issues of 'use', 'play' and '(built) environment', which usually examines the associations between features of built environment and users' activities; the theme, 'environmental conservation', can be related to the issues of '(ecological) service(s)', '(stormwater) management', 'environment' , 'pollution (treatment)', 'preservation' and 'conservation'; the theme, 'development management', can be related to the issues of 'development' and '(development) management'; the theme, 'nature', can be related to the issues of 'wilderness', 'plant', 'soil' and 'bird'; and the theme, 'public benefits', can be related to the issues of 'beauty' and '(public) health '. These six themes, 'professional practices', 'park use', 'environmental conservation', 'development management', 'nature' and 'public benefits', can help understanding the main interest shown by the researchers.

Different Research Interest Shown by Landscape Architects and the Other Experts. The relatively stable publications in the journal indicate the importance of urban park research to the profession of landscape architecture. When landscape architects have been concerning themselves with urban parks, more and more experts from other disciplines joined, or are joining, in this field with rapidly increasing publications.

Relating the six themes to the major issues that were discussed by the two groups of experts (see Fig. 5), the focal interest shown by landscape architects was obviously limited in 'professional practices'. But for experts from various disciplines, more diverse research interest was included. The themes of 'environmental conservation', 'nature' , 'development management' and 'public benefits' refer to wider concerns of scientific attitudes and social responsibilities.

Changes of Research Interest over the Last Three Decades. Fig. 5 also exhibits the evolution of research interest over the periods. It can be perceived that the work of the two expert groups has been converging with gradually diverse research interest. 
In the periods of 1983-1993and 1994-1998, landscape architects mainly cared about the issues of planning and design. Another issue, 'use', studied how parks could promote more and better park use so that the work of planning or design could be better supported. In the periods of 1999-2003, 2004-2008 and 2009-2013, landscape architects began to broaden their research interest into some issues related to the more scientific or responsible themes of 'nature', 'development management', 'public benefits' and 'environmental conservation', besides their professional practices.

For experts from other disciplines, the themes of 'environmental conservation' and 'nature' were the original concerns. But from the period of 1999-2003, the professional issues, not only designing and planning but also managing and modeling, have become important subjects under discussion. The theme of 'professional practices' emerged besides 'development management', 'park use', 'public benefits' and 'environmental conservation'.

The periods of 1999-2003 and 2004-2008 witnessed a gradual boom of diversified research in both expert groups. Besides the original concerns, landscape architects and experts from other disciplines began to pay attention to each other's research interest. 'Development management' became the common care to deal with conflicts between urbanization and park development.

However, in the periods of 2009-2013, the diversification of research interest decreased. Besides 'professional practices', the experts' concerns focused on environmental and social benefits of urban parks, i.e. 'environmental conservation' and 'public benefits'. This inverse diversification might indicate that against the increasingly complicated urban background, sustainable development of urban parks should look back to parks' primary functions and exert more rational practices.

Inspiration and Challenge to Landscape Architects. Records indexed by WSCC provide the evidence that more experts from various professional areas joined in urban park research recently (see Fig.1) and they are creating rapidly increasing articles (see Fig. 2) to nurture scholarship in landscape architecture. Their research interest coincided with those of landscape architects substantially but fell in broader scope. In many cases there were more in-depth explorations from multi-disciplinary points of view in their studies.

Landscape architects should resist this intrusion upon the important, traditional field of the profession. However, this may impel them to reflect on the next move. Landscape architecture is an ever changing profession [10]. It is far more than just design and has a role to play in addressing issues of importance in the world today, such as global climate change, urban heat islands, mass migration to urban areas and loss of biological diversity [20]. Other experts' extensive studies may provide useful facts and knowledge to the professional practices of landscape architecture. A multi-disciplinary integration may be evolved from the current intrusion in the field of urban park research.

\section{Conclusions}

Landscape architects have been studying urban parks to sustain the urban environment and increase the quality of people's everyday life. Recently more experts from various professional areas joined in this field, brought rapidly increasing publications and broadened the research interest. Their extensive and in-depth studies may nurture landscape architects and inspire the development of sustainable urban park system. Landscape architects should shoulder more social responsibilities in the evolution of multi-disciplinary integration.

\section{Acknowledgements}

Supports from key project research funding of Tongji Architectural Design (Group) Co., Ltd. and Key Laboratory of Ecology and Energy-saving Study of Dense Habitat (Tongji University), Ministry of Education (Grant No.2015KY06), Innovation and Quality Project of National Undergraduate Education in China (The Trial Comprehensive Reform in Landscape Architecture Discipline, Grant No. Higher Education Department [2014]2) are acknowledged. 

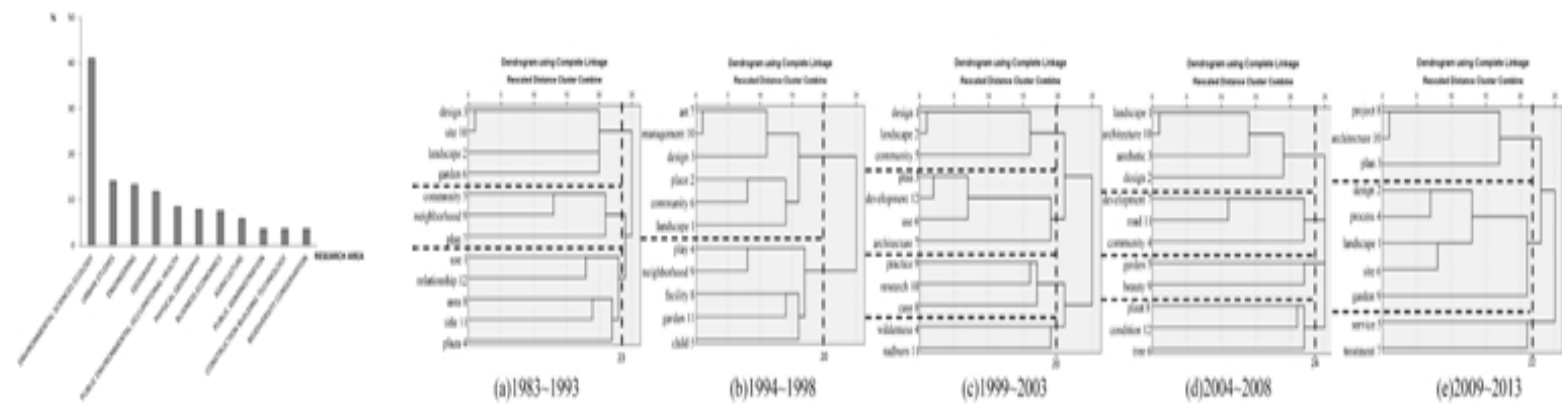

Fig, 1. Percentages of records in differentresearch areas

Fig, 3(a)-3(e), Co-word cluster trees for groups of documents published in $L J$

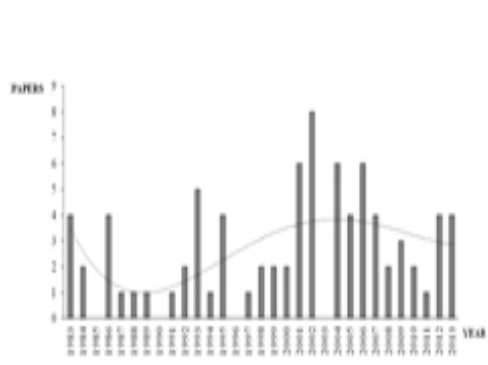

Fig,2(a), Yearly publications in $L J$

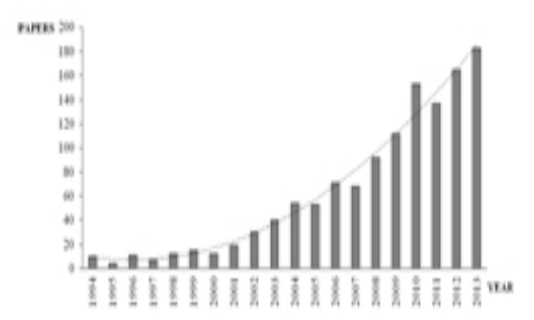

Fig,2(b), Yearly publications that were indexed by WSCC
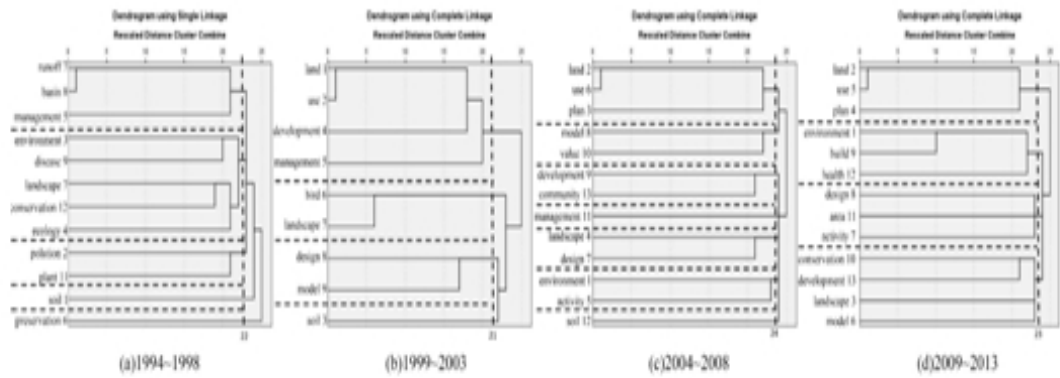

Fig, 4(a)-4(d). Co-word cluster treas for groups of documents indexed by WSCC

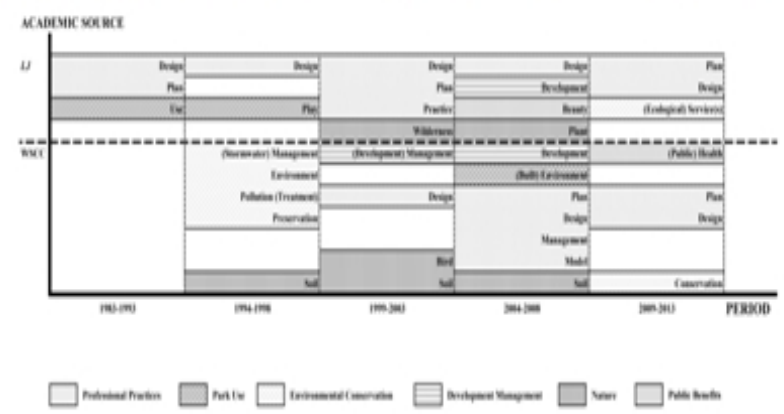

Fig.5. Themes shared by the major issues of record groups over the periods 
Table2. Top words for co-word analyses by group

\begin{tabular}{|c|c|c|c|c|c|c|c|c|c|c|c|}
\hline Acsdemic & No. & $1983 \cdot 1993$ & & $1994-1998$ & & $1999-2003$ & & $2004-2008$ & & $2009 \cdot 2013$ & \\
\hline Soures & & Word & Frequency & Word & Frequency & Word & Frequency & Word & Frequency & Word & Frequency \\
\hline$\overline{L J}$ & 1 & Use & 22 & Landacspe & 15 & Dasign & 38 & Landicape & 39 & Landicspe & 37 \\
\hline & 2 & Landicspe & 21 & Place & 10 & Landicape & 37 & Dasign & 35 & Dasign & 32 \\
\hline & 3 & Dasign & 18 & Dasign & 8 & Plan & 25 & Aesthatic & 14 & Plan & 13 \\
\hline & 4 & Plana & 18 & Play & 6 & Wildemess & 21 & Community & 13 & Process & 10 \\
\hline & 5 & Community & 11 & Child & 4 & Community & 19 & Garden & 12 & Service & 9 \\
\hline & 6 & Garden & 9 & Commurity & 4 & Une & 18 & Tres & 12 & Site & 9 \\
\hline & 7 & Plan & 8 & Ant & 3 & Architecture & 17 & Development & 11 & Trestment & 8 \\
\hline & 8 & Ares & 8 & Facility & 3 & Cas & 16 & Plant & 11 & Projest & 8 \\
\hline & 9 & Neighborhood & 6 & Neighborhood & 3 & Practice & 12 & Besaty & 9 & Garden & 7 \\
\hline & 10 & Site & 6 & Mangegement & 3 & Research & 12 & Architecture & 8 & Architecture & 7 \\
\hline & 11 & Title & 6 & Garden & 3 & Radbum & 11 & Rosd & 8 & & \\
\hline & 12 & Relationship & 6 & & & Development & 11 & Condition & 8 & & \\
\hline & 13 & & & & & Place & 10 & & & & \\
\hline & 14 & & & & & Model & 10 & & & & \\
\hline & 15 & & & & & Neighborhood & 9 & & & & \\
\hline WSCC & 1 & & & Soil & 7 & Land & 22 & Environment & 49 & Environment & 128 \\
\hline & 2 & & & Pollution & 5 & Use & 15 & Land & 44 & Land & 112 \\
\hline & 3 & & & Enviromment & 4 & Soil & 13 & Plan & 41 & Landicspes & 78 \\
\hline & 4 & & & Ecology & 4 & Davelopment & 10 & Landicape & 30 & Plan & 68 \\
\hline & 5 & & & Naragement & 4 & Manggement & 9 & Activity & 29 & Une & 67 \\
\hline & 6 & & & Preservation & 3 & Bird & 8 & Une & 29 & Model & 67 \\
\hline & 7 & & & Runoff & 3 & Landscape & 8 & Dasign & 28 & Activity & 60 \\
\hline & 8 & & & Basin & 3 & Dasign & 8 & Model & 26 & Dasign & 57 \\
\hline & 9 & & & Digases & 3 & Model & 8 & Development & 25 & Build & 46 \\
\hline & 10 & & & Landacape & 3 & & & Value & 23 & Conservation & 45 \\
\hline & 11 & & & Plant & 3 & & & Menggement & 23 & Area & 45 \\
\hline & 12 & & & Conservation & 3 & & & Soil & 23 & Health & 45 \\
\hline & 13 & & & & & & & Community & 21 & Dsvelopment & 44 \\
\hline
\end{tabular}


Table 3. Major research is sues interpreted for each group

\begin{tabular}{|c|c|c|c|c|c|c|c|c|c|c|}
\hline $\begin{array}{l}\text { Acadeni: } \\
\text { Sorace }\end{array}$ & $\begin{array}{l}1993 \cdot 1993 \\
\text { Ins: }\end{array}$ & $\begin{array}{l}\text { Woots of Hight } \\
\text { Fetpuasy }\end{array}$ & $\begin{array}{l}1994+1998 \\
1 \text { lus: }\end{array}$ & $\begin{array}{l}\text { Worts of Hight } \\
\text { Fatpasyy }\end{array}$ & $\begin{array}{l}1999 \cdot 2003 \\
\text { Ins: }\end{array}$ & $\begin{array}{l}\text { Wods of Hizh } \\
\text { Fetpuary }\end{array}$ & $\begin{array}{l}2004-2008 \\
15 x=\end{array}$ & $\begin{array}{l}\text { Wods of Hight } \\
\text { Fregauacy }\end{array}$ & $\begin{array}{l}2000 \cdot 2013 \\
\text { Ins: }\end{array}$ & $\begin{array}{l}\text { Woods of High } \\
\text { Frequeacy }\end{array}$ \\
\hline \multirow[t]{4}{*}{$\bar{L}$} & Detign & $\begin{array}{l}\text { Design; Sin; } \\
\text { Luadrapt; } \\
\text { Gaden }\end{array}$ & Design & $\begin{array}{l}\text { Art, } \\
\text { Masagemeat; } \\
\text { Desiza; Pace; } \\
\text { Commuity; } \\
\text { Ladruapt }\end{array}$ & Design & $\begin{array}{l}\text { Desiga; } \\
\text { Ludusp; } \\
\text { Commicing }\end{array}$ & Design & $\begin{array}{l}\text { Ladfrape; } \\
\text { Archactur; } \\
\text { Astastr; Design }\end{array}$ & Pla & $\begin{array}{l}\text { Roject, Archiactes; } \\
\text { Pan }\end{array}$ \\
\hline & Pan & $\begin{array}{l}\text { Commoiny, } \\
\text { Neighborbot; } \\
\text { Pas }\end{array}$ & Pay & $\begin{array}{l}\text { Pay; } \\
\text { Neighbobood; } \\
\text { Faciln; Gardea; } \\
\text { Caid }\end{array}$ & Pha & $\begin{array}{l}\text { Par; } \\
\text { Developeneat, } \\
\text { Us;; } \\
\text { Archactest }\end{array}$ & Developmeat & $\begin{array}{l}\text { Develspeneat, } \\
\text { Rosd, Conmencity }\end{array}$ & Design & $\begin{array}{l}\text { Desiga; Rocen; } \\
\text { Luabuape; Sn; } \\
\text { Gudea }\end{array}$ \\
\hline & Un: & $\begin{array}{l}\text { Un; } \\
\text { Resusoubin; } \\
\text { Asts; Tdt; Pan }\end{array}$ & & & Resucth & $\begin{array}{l}\text { Procise; } \\
\text { Renuch; Can }\end{array}$ & Bavy & Gardea; Beswy & $\begin{array}{l}\text { (Ecologika!) } \\
\text { Stanist(s) }\end{array}$ & Senve; Tresmeat \\
\hline & & & & & Wadereess & $\begin{array}{l}\text { Wibteras, } \\
\text { Rafures }\end{array}$ & Past & $\begin{array}{l}\text { Past; Cooditisa; } \\
\text { Tres }\end{array}$ & & \\
\hline \multirow[t]{7}{*}{ WSOC } & & & $\begin{array}{l}\text { (Stromevats) } \\
\text { Masagement }\end{array}$ & $\begin{array}{l}\text { Fuosfi, Buin; } \\
\text { Wasgemet }\end{array}$ & $\begin{array}{l}\text { Developmest } \\
\text { Masagement }\end{array}$ & $\begin{array}{l}\text { Lad; Us: } \\
\text { Developmeet; } \\
\text { Masagemeat }\end{array}$ & Pas & Luat; Uss; Pas & Pla & Last; Us; Pas \\
\hline & & & $\begin{array}{l}\text { Envoumeat } \\
\text { Coasurvisa }\end{array}$ & 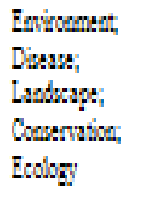 & Bird & Bind; Ladtrapt & Mode! & Model; Valze & (Pobic) Hath & $\begin{array}{l}\text { Envroemest, Bold, } \\
\text { Hesth }\end{array}$ \\
\hline & & & $\begin{array}{l}\text { Pollosion } \\
\text { (Tresmet) }\end{array}$ & Pollesica; Past & Design & Design; Mode! & Developpmest & $\begin{array}{l}\text { Developmeat; } \\
\text { Commeity }\end{array}$ & Design & Desiga; Ares; Actinty \\
\hline & & & soid & soid & soit & Sod & Masagemeat & Masagemeat & Coaservasisa & 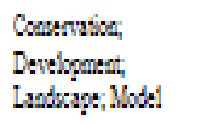 \\
\hline & & & Resarasica & Restrasisa & & & Design & $\begin{array}{l}\text { Lastrape; } \\
\text { Design }\end{array}$ & & \\
\hline & & & & & & & $\begin{array}{l}\text { (Boil) } \\
\text { Envinoment }\end{array}$ & $\begin{array}{l}\text { Eervoment } \\
\text { Activiny }\end{array}$ & & \\
\hline & & & & & & & Sod & Sold & & \\
\hline
\end{tabular}




\section{References}

[1] Information on http://www.cabe.org.uk/publications/the-value-of-public-space

[2] C. W.Thompson: Landscape and Urban Planning Vol. 99 (2011) , p. 187-195

[3] G. Cranz: The politics of park design: A history of urban parks in America (Massachusetts Institute of Technology Press, USA 1983).

[4] G. C. Godbey, L. L. Caldwell, M. Floyd and L. L. Payne: American Journal of Preventive Medicine Vol. 28(2005), p. 150-158

[5] Information on http://www.cabe.org.uk/publications/urban-green-nation

[6] P. Harnik: The Excellent City Park System: What Makes it Great and How to Get There (Trust for Public Lands, USA 2006).

[7] Information on http://connection.ebscohost.com/c/speeches/2215444/next-1000-years

[8] C. W. Thompson: Landscape and Urban Planning Vol. 60, (2002) , p. 59-72

[9] M. Laurie: An Introduction to Landscape Architecture (Elsevier Science Publication, US 1986).

[10] E. H. Zube: Landscape and Urban Planning Vol. 42 (1998), p. 75-80

[11] P. H. Gobster, J. I. Nassauer and D. J. Nadenicek: Landscape Journal Vol. 29 (2010), 52-70

[12] A. Leger, W. Oueslati and J. Salanie: Landscape and Urban Planning Vol. 116 (2013), p. 13-24

[13] T. Dehdarirad, A. Villarroya and M. Barrios: Scientometrics Vol. 101 (2014), p. 273-290

[14] J. Zhang, J. Xie, W. Hou, X. Tu, J. Xu, F. Song and Z. Lu: Plos One Vol. 7 (2012) , p.1

[15] M. Callon, J. P. Courtial and F. Laville: Scientometrics Vol. 22 (1991), p. 155-205

[16] J.G. Fabos: Landscape and Urban Planning Vol. 68 (2004), p. 321-342

[17] M. Nobis and T. Wohlgemuth: Oikos Vol. 106 (2004), p. 411-421

[18] A. Yang, X. Ma, F. Zhang and W. Xue: Journal of Intelligence Vol. 31 (2012), p. 52-55, 74

[19] J. C. Donohue: Understanding Scientific Literature: A Bibliometric Approach (MIT Press, USA 1973).

[20] R. D Brown and R. C. Corry: Landscape and Urban Planning Vol. 100 (2011), p. 327-329 